\title{
Los Autores
}

\section{JaVier Rodríguez Weber}

Doctor en Historia Económica por la Universidad de la República (Uruguay). Docente de dedicación total en el Programa de Historia Económica y Social de la Universidad de la República (Uruguay), fue premiado por la Asociación Española de Historia Económica con el Premio Ramón Carande 2011 al mejor artículo en Historia Económica escrito por un investigador iberoamericano menor de 35 años. Su principal línea de investigación refiere al estudio de la economía política de la desigualdad en América latina en el largo plazo, es autor de Desarrollo y Desigualdad en Chile (1850-2009). Historia de su economía política, libro basado en su tesis doctoral, próximo a publicarse por la Dirección de Bibliotecas Archivos y Museos de Chile (DIBAM). Es coautor, junto con Luis Bértola,"Latin American Economic History: looking backwards for the future", en: Routledge Handbook of Global Economic History. Editado por Francesco Boldizzoni y Patricia Hudson. Routledge, 2016, pp. 329-342.

\section{Cristián Ducoing Ruiz}

Doctor en historia económica por la Universidad de Barcelona y actualmente es investigador postdoctoral en el departamento de geografía e historia económica de la Universidad de Umeå, Suecia. Su trabajo cubre diversas áreas de la historia económica, como cuentas nacionales históricas, recursos naturales, industrialización y desarrollo. Ha publicado en revistas del área, como Australian Economic History Review y América Latina en la Historia Económica junto con capítulos temáticos en dos libros. Sus investigaciones en curso están relacionadas con energía (la relación entre energía y capital físico en maquinaria específicamente), el ahorro genuino de los países en el largo plazo (trabajo en conjunto con Matthias Blum y Eoin McLaughlin), industrialización en Chile (Con Marc Badia y Cecilia Lara) y los efectos de las dictaduras en el desarrollo (Con Sara Torregrosa). 


\section{Alejandro Schneider}

Doctor en Historia, Facultad de Humanidades y Ciencias de la Educación Universidad Nacional de La Plata (UNLP). Licenciado y Profesor en Historia, Facultad de Filosofía y Letras Universidad de Buenos Aires (UBA). Profesor-Investigador de la Facultad de $\mathrm{Hu}-$ manidades y Ciencias de la Educación, Universidad Nacional de La Plata e Instituto de Historia Argentina y Americana "Dr. Emilio Ravignani”, Facultad de Filosofía y Letras de la Universidad de Buenos Aires. Profesor visitante de Posgrado en la Universidad de Buenos Aires, Universidad de Puerto Rico (Puerto Rico), Instituto Mora (México). Es autor de Los compañeros. Trabajadores, izquierda y peronismo (1955-1973) y coautor de Miradas sobre el genocidio armenio, Entre el Orden y la Revolución. América Latina en el siglo XX y Los Setentistas. Izquierda y clase obrera: 1969-1976, entre muchos otros.

\section{Daniel Cabral Marques}

Profesor en Historia por la Universidad Nacional de la Patagonia "San Juan Bosco" y Magíster en Historia por la Universidad Nacional de Mar del Plata. Próximamente defenderá la tesis de Doctor en Historia en la Universidad Nacional del Centro de la Provincia de Buenos Aires titulada: "Las empresas estatales extractivas y la configuración de identidades sociales ligadas al mundo del trabajo en la Patagonia Austral a lo largo del siglo XX: Origen, desarrollo y desarticulación”. Académico permanente en la Universidad Nacional de la Patagonia "San Juan Bosco" y Universidad Nacional de la Patagonia Austral. Investigador III en el Sistema Nacional de Categorización de Docentes-Investigadores (Argentina). Miembro del Grupo de Estudios de Historia Social de la Patagonia Central y Austral (GEHISO-Pa. Ce.Al.) y del Instituto sobre Trabajo, Economía y Territorio (ITET). Ha escrito numerosos trabajos, entre los que podemos mencionar: "Los mineros del carbón en el Yacimiento de Río Turbio durante el periodo territoriano: Identidades sociolaborales, frontera e inversión estatal en una "periferia" de la nación", en Enrique Mases y Mirta Zink (comp.): En la vastedad del “desierto"... Estado, prácticas y actores sociales (1884-1958), № 4, Colección Estudios y Problemas, Editorial 
de la Universidad Nacional de La Pampa - Prohistoria, 2014; "La constitución de una "gran familia": trabajadores e identidades sociolaborales en las empresas extractivas estatales de la Patagonia Austral", en Daniel Dicósimo y Silvia Simonassi (compiladores): Trabajadores y empresarios en la Argentina del siglo XX: indagaciones desde la historia social, Prohistoria Ediciones, Rosario, 2011.

\section{Sara Torregrosa-Hetland}

Actualmente es investigadora postdoctoral en el Departamento de Historia Económica de la Universidad de Lund (Suecia). Desarrolló su tesis de doctorado, titulada "Sistema fiscal y redistribución: la transición fiscal española (1960-1990)", entre 2011 y 2015 en la Universidad de Barcelona, Departamento de Historia e Instituciones Económicas. Durante dicha etapa doctoral realizó estancias de investigación en la Universidad de Berkeley (CA, EE.UU.) y la Universidad de Umeå (Suecia). Entre sus recientes publicaciones se incluyen: "Did Democracy bring Redistribution? Insights from the Spanish tax system (1960-1990)", European Review of Economic History 19:3 (2015), pp. 294-315; y "Sticky income inequality in the Spanish transition, 1973-1990", Revista de Historia Económica 34:1 (2016), pp. 39-80. Sus proyectos actuales de investigación se dirigen a seguir explorando la desigualdad, las reformas fiscales y el fraude fiscal en una perspectiva internacional. 